\title{
Nicotinic Receptors Concentrated in the Subsynaptic Membrane Do Not Contribute Significantly to Synaptic Currents at an Embryonic Synapse in the Chicken Ciliary Ganglion
}

\author{
Peter B. Sargent \\ Department of Cell and Tissue Biology and the Neuroscience Graduate Program, University of California, San Francisco, San Francisco, California 94143-0640
}

\begin{abstract}
Rapid synaptic transmission at the calyciform synapse in the embryonic chicken ciliary ganglion is mediated by two classes of nicotinic receptors: those containing $\alpha 3$ subunits [ $\alpha 3$-nicotinic ACh receptors (nAChRs)] and those containing $\alpha 7$ subunits ( $\alpha 7-\mathrm{nAChRs).} \alpha 3$ $\mathrm{nAChRs}$ and $\alpha 7$-nAChRs are differentially distributed on the cell surface; $\alpha 3$-nAChRs are concentrated at postsynaptic densities, whereas both $\alpha 7$-nAChRs and $\alpha 3$-nAChRs are found extrasynaptically on somatic spines. I explored the contribution of $\alpha 3$-nAChRs and $\alpha 7$ nAChRs to uniquantal responses, measured as MEPSCs, or as evoked responses under low release probability conditions. The contribution that each nAChR makes to uniquantal response shape was determined by blocking one nAChR type; pharmacologically isolated $\alpha 7$-nAChR responses were kinetically fast (rise time, $0.32 \pm 0.02 \mathrm{~ms}$; decay time, $1.66 \pm 0.18 \mathrm{~ms}$; mean $\pm \mathrm{SD} ; n=6$ cells), whereas pharmacologically isolated $\alpha 3$-nAChR responses were slow (rise time, $1.28 \pm 0.35 \mathrm{~ms}$; decay time, $6.71 \pm 1.46 \mathrm{~ms} ; n=8$ cells). In the absence of antagonists, most cells (11 of 14) showed heterogeneity in the kinetics of uniquantal responses, with $\sim 25 \%$ of events exhibiting fast, $\alpha 7$-nAChR-like kinetics and $\sim 75 \%$ of events exhibiting the kinetics expected of coactivation of $\alpha 7$-nAChRs and $\alpha 3$-nAChRs. Cells rarely showed significant numbers of uniquantal responses with slow, $\alpha 3$-nAChR-like kinetics, which was unexpected given that $\alpha 3$ $\mathrm{nAChRs}$ alone are concentrated at postsynaptic densities. The only site where ACh quanta can activate both $\alpha 3$-nAChRs and $\alpha 7$-nAChRs readily is on the somatic spines, where $\alpha 7$-nAChRs and $\alpha 3$-nAChRs are present extrasynaptically. At the calyciform synapse, rapid synaptic transmission is mediated apparently without participation of ionotropic receptors concentrated at postsynaptic densities.
\end{abstract}

\section{Introduction}

Nicotinic ACh receptors (nAChRs) underlie rapid transmission at vertebrate skeletal nerve-muscle synapses and at ganglionic synapses but not widely in the CNS, where nAChRs are often located extrasynaptically or presynaptically and play a modulatory role (MacDermott et al., 1999; Wonnacott et al., 2006; Dani and Bertrand, 2007). nAChR expression in the CNS is diverse, and there is evidence that homomeric $\alpha 7$ subunit-containing nAChRs ( $\alpha 7$-nAChRs) play different functional roles than do heteromeric non- $\alpha 7$-nAChRs (Picciotto et al., 2008). This system can be modeled by the embryonic chicken ciliary ganglion, where both $\alpha 7$-nAChRs and non- $\alpha 7$-nAChRs are expressed and where nAChRs are located extrasynaptically and presynaptically.

\footnotetext{
Received 0ct. 23, 2008; revised Jan. 16, 2009; accepted Feb. 15, 2009.

This work was supported by National Institutes of Health Grant R01 MH068690 and by intramural grants from the University of California, San Francisco (UCSF) Academic Senate and from the UCSF Resource Evaluation and Allocation Committee. These experiments were begun by Dr. Anna Windle. I thank Philippe Ascher for quidance and for participating in experiments, Stephen Traynelis for assistance with ChannelLab, Jason Rothman for assistance with Neuromatic, Michael McIntosh for the gift of $\alpha$-conotoxin MIl, Jackie Pisenti and the Avian Facility at the University of California, Davis for supplying chick embryos, and Philippe Ascher, Jay Coggan, and Joseph Margiotta for comments on this manuscript.

Correspondence should be addressed to Dr. Peter B. Sargent, Department of Cell and Tissue Biology, Box 0640, University of California, San Francisco, San Francisco, CA 94143-0640. E-mail: peter.sargent@ucsf.edu. D0I:10.1523/JNEUROSCI.5404-08.2009

Copyright $\odot 2009$ Society for Neuroscience $\quad$ 0270-6474/09/293749-11\$15.00/0
}

Embryonic chicken ciliary neurons are supplied by a calyciform terminal (Dryer, 1994), anatomically similar to the calyx of Held. Ciliary neurons lack dendrites but have somatic spines; synaptic contacts are present on the spines (Shoop et al., 1999), but $\sim 90 \%$ are located on the soma (Nguyen and Sargent, 2002). Ciliary neurons express homomeric $\alpha 7$-nAChRs and a heterogeneous population of nAChRs containing $\alpha 3, \alpha 5$, and $\beta 4$ subunits (Vernallis et al., 1993; Conroy and Berg, 1995). The $\alpha 3$ containing nAChRs ( $\alpha 3$-nAChRs) are concentrated at postsynaptic densities (PSDs) (Jacob et al., 1984; Loring and Zigmond, 1987) and are also present on spines (Jacob et al., 1984; Horch and Sargent, 1995; Shoop et al., 1999). $\alpha 7$-nAChRs are diffusely distributed on spines (Jacob and Berg, 1983; Horch and Sargent, 1995; Shoop et al., 1999) and are also located presynaptically (Coggan et al., 1997; Rogers and Sargent, 2003).

One challenge to understanding synaptic transmission onto chick ciliary neurons is to determine how nerve-released ACh activates $\alpha 7$-nAChRs (Zhang et al., 1996; Ullian et al., 1997), given that most of them are extrasynaptic. Using electron microscopy, Shoop et al. (1999) reported docked synaptic vesicles and presynaptic " $\Omega$ figures" at extrasynaptic sites on somatic spines and suggested that transmitter might be released ectopically onto $\alpha 7$-nAChRs. Using the MCell modeling environment, Coggan et al. (2005) compared the distribution of mEPSCs with that ex- 
pected if release occurred from docked vesicles within a reconstructed portion of the synapse according to one of three release models: active zone based, ectopic only, or mixed. The best fit to the experimental data was obtained with the ectopic-only model. The conclusions of Coggan et al. (2005) are provocative, not only because ectopic release has not been widely documented at interneuronal synapses (Matsui and Jahr, 2006), but also because we previously reported the stimulation- and calcium-dependent uptake and release of extracellular tracer at synaptic contacts on ciliary neurons (Nguyen and Sargent, 2002). Because there is release at synaptic contacts, and because release onto $\alpha 3-\mathrm{nAChRs}$ at PSDs should produce kinetically slow mEPSCs (Zhang et al., 1996; Ullian et al., 1997; Chen et al., 2001), I examined mEPSC kinetics in hopes of characterizing responses to conventional release. Kinetically slow mEPSCs are rare, whereas kinetically fast mEPSCs, produced by the activation, in whole or in part, of $\alpha 7$ $\mathrm{nAChRs}$, are common. This suggests that ionotropic receptors clustered at PSDs play only a minor role in mediating rapid transmission at this embryonic synapse.

\section{Materials and Methods}

Animal procedures were done in accordance with the University of California, San Francisco Institutional Animal Care and Use Committee. Chick embryos were obtained from the Avian Facility at the University of California, Davis and were kept in a forced draft incubator at $36-37^{\circ} \mathrm{C}$ and $50-55 \%$ relative humidity until $14-15 \mathrm{~d}$ of incubation (E14-E15; Hamilton \& Hamburger stages 39-41). Embryos were killed by decapitation, and ciliary ganglia were dissected in HEPES-buffered saline (147.5 $\mathrm{mm} \mathrm{NaCl}, 4 \mathrm{~mm} \mathrm{KCl}, 2 \mathrm{~mm} \mathrm{CaCl}, 1 \mathrm{MgCl}_{2}, 10 \mathrm{~mm}$ glucose, and $10 \mathrm{~mm}$ HEPES, pH 7.4, milliosmolarity: 310-315). Most experiments were performed in bicarbonate-buffered chick saline ( $130 \mathrm{~mm} \mathrm{NaCl}, 4 \mathrm{~mm} \mathrm{KCl}, 2$ $\mathrm{mm} \mathrm{CaCl}, 1 \mathrm{~mm} \mathrm{MgCl}_{2}, 10 \mathrm{~mm}$ glucose, $1 \mathrm{~mm} \mathrm{Na}_{2} \mathrm{HPO}_{4}, 25 \mathrm{~mm}$ $\mathrm{NaHCO}_{3}$, pH buffered to 7.4 by bubbling with $95 \% \mathrm{O}_{2}-5 \% \mathrm{CO}_{2}$, milliosmolarity: $310-315)$. Internal solution was either $135 \mathrm{~mm} \mathrm{CsCl}, 10.6$ mM HEPES, 1.7 mм EGTA, 4.3 mm glucose, $1.8 \mathrm{~mm}$ ATP, $0.2 \mathrm{~mm}$ GTP, and $5 \mathrm{~mm}$ QX-314, pH 7.2, or $120 \mathrm{~mm}$ Cs methanesulfonate, $15 \mathrm{~mm}$ TEA-Cl, 10 mм EGTA, 10 mм HEPES, 2 mм ATP, 0.2 mm GTP, and 5 mm QX-314, pH 7.2 (with CsOH), milliosmolarity: 285-295. $\alpha$-Conotoxin MII, a gift from Dr. Michael McIntosh (University of Utah, Salt Lake City, UT), was used at 300 nM in HEPES-buffered saline (as above) without bubbling and in the presence of $0.1 \mathrm{mg} / \mathrm{ml}$ protease-free bovine serum albumin. Reagents were obtained from Sigma-Aldrich except methyllycaconitine and QX-314, which were obtained from Tocris Bioscience. All experiments were done at room temperature $\left(21-23^{\circ} \mathrm{C}\right)$.

Whole-cell recordings were made from ciliary neurons according to standard procedures (Hamill et al., 1981) using an Axopatch 200B amplifier (Molecular Devices). Synaptic currents elicited from the soma of ciliary neurons should be recorded under conditions of good space clamp (Shoop et al., 1999), because these cells have no dendrites and because their spines have approximately the same dimensions as spines of neurons in the mammalian CNS, where there is general agreement that the voltage drop across the spine neck is negligible (Segev and Rall, 1988; Harris and Stevens, 1989; Koch and Zador, 1993; Svoboda et al., 1996). Patch pipettes were made from $1.5 \mathrm{~mm}$ thin-walled borosilicate glass and had initial resistances of 1.6-3.0 $\mathrm{M} \Omega$. The surface of the ciliary ganglion was cleaned by local perfusion with purified collagenase and thermolysin (Roche Pharmaceuticals; Liberase III) delivered with a pressure of 0.5$2.0 \mathrm{kPa}$ for 5-30 min via a patch pipette with an internal tip diameter of 3-5 $\mu \mathrm{m}$ [modified from Yawo and Chuhma (1994)]. On-cell and wholecell recordings from satellite cells, calyciform presynaptic terminals, and ganglion cells were distinguished on the basis of the response to brief electrical stimulation via a suction electrode to the preganglionic nerve. Ciliary neurons were distinguished from choroid neurons by their size (McNerney et al., 2000) and by having a single, large synaptic input (Ullian et al., 1997) preceded by a capacitative signal that marks the arrival of the presynaptic action potential in the terminal (Forsythe, 1994). Ciliary neurons, which had a membrane capacitance of $34 \pm 7 \mathrm{pF}$, were voltage clamped generally at $-60 \mathrm{mV}$, and synaptic currents were filtered at 2 or $5 \mathrm{kHz}$ using the Axopatch 200B's four-pole Bessel filter and digitized at $10-20 \mathrm{kHz}$. No correction was made for liquid junction potential. Series resistance was monitored during the recording; data were pooled, or compared, provided that series resistance did not change by $>25 \%$ over the course of the experiment. Experiments were discontinued if uncompensated series resistance exceeded $10 \mathrm{M} \Omega$ or if the holding current exceeded $-100 \mathrm{pA}$. Series resistance compensation (80\%) was used either during the recordings using the Axopatch 200B or afterward using ChannelLab (Synaptosoft) and using the correction for a nonlinear $I-V$ curve (see Fig. $1 D$ ). Synaptic currents were analyzed using a combination of Mini Analysis (Synaptosoft) and Neuromatic (ThinkRandom; Jason Rothman) implemented in Igor Pro (Wavemetrics). Except for the data in Figure 7, mEPSCs were analyzed after being curve-fit in Neuromatic using an equation modified from Bekkers and Clements (1999). Fits were confirmed by manual inspection. Current traces showing mEPSCs displayed in figures were smoothed in Igor Pro (binomial; $n=3$ ), except for Figure 3A2. "Rise time" in the text is 10-90\% rise time, and "decay time" is measured from the peak as area/peak. I found no correlation across cells between mEPSC amplitude, mEPSC rise time, or mEPSC decay time and (1) cell capacitance, (2) cell input resistance, (3) uncompensated pipette access resistance, (4) "settling time" of the electronics (the $\tau$ for relaxation of the current during a small step change in potential), (5) the filtering on the Axopatch 200B (2 or $5 \mathrm{kHz}$ ), (6) the root mean square noise level of the recording, or (7) the holding current.

Because the rate of spontaneous release is usually low, I generated asynchronous mEPSCs by stimulating the preganglionic nerve at $2-4 \mathrm{~Hz}$ in the presence of strontium. In a sample of recordings where at least 10 spontaneous events were detected, the mEPSCs produced by this approach are similar in size to "true" spontaneous mEPSCs $(n=8$; six comparisons showed no difference by $t$ test, $p>0.05$; in one comparison, spontaneous events were $\sim 30 \%$ larger than asynchronous events, and in one comparison, spontaneous events were $\sim 25 \%$ smaller, $p<0.05$ by $t$ test). Asynchronous mEPSCs produced by stimulation in strontium rarely contained slowly rising events expected with activation solely of $\alpha 3$-nAChRs (see Results). To explore whether this might be an artifact related to the use of enzyme to clean the cell surface or to the mechanical procedures required to establish gigohm seal recordings from ciliary neurons, I performed two studies. In one study, I looked for a correlation between the time of enzyme exposure and EPSC kinetics to test the hypothesis that enzyme treatment leads to a loss of activation of $\alpha 3$ nAChRs, which would be manifest as a reduction in the decay time of the EPSC. In this study, I recorded EPSCs from cells exposed to enzyme for $2-6 \min (n=4$ cells), for $10 \min (n=10)$, and for $15 \min (n=9)$; by one-way ANOVA, I found no difference in EPSC amplitude, rise time, or decay time across the samples $(0.13<p<0.35)$. Thus, there is no suggestion that typical enzyme exposure (15-20 min) alters EPSC properties as compared with brief exposure. In the second set of experiments, I used sharp electrodes (resistance, 30-90 M $\Omega$ ) to compare EPSC properties in enzyme-treated ganglia with those in intact ganglia not treated with enzyme. Because of filtering through the high series resistance of the sharp electrode, EPSCs were smaller and slower when recorded using sharp electrodes. I found no difference in EPSC amplitude or decay time between untreated and enzyme-treated (20 min) ganglia [EPSC amplitude, $90 \pm 145 \mathrm{pA}$ (untreated, $n=6$ ) and $126 \pm 127 \mathrm{pA}$ (treated, $n=10$ ), $p=0.62$; EPSC decay time, $7.3 \pm 1.5 \mathrm{~ms}$ (untreated) and $11.4 \pm 6.1 \mathrm{~ms}$ (treated), $p=0.12$ ]. These results suggest that enzyme treatment does not preferentially reduce activation of $\alpha 3$-nAChRs by nerve-released transmitter and that the failure to detect $\alpha 3$-nAChR mEPSCs is not likely to be caused by the methods used to acquire gigohm seals from ciliary neurons. To explore the possibility that some essential component within the ciliary neuron cell body was dialyzed out by exchange with the contents of the patch pipette, I collected strontium mEPSCs from cells using the perforated-patch technique. In a sample of eight cells, with 250-600 mEPSCs analyzed per cell, mEPSC amplitude was $-43.1 \pm$ $12.1 \mathrm{pA}, \mathrm{mEPSC}$ rise time was $0.39 \pm 0.10 \mathrm{~ms}$, and $\mathrm{mEPSC}$ decay time was $2.42 \pm 0.69 \mathrm{~ms}$; these samples are not different than those collected using conventional whole-cell patch methods $(0.31<p<0.64$; Student's $t$ test). Moreover, an analysis of rise time probability density functions of 
these cells (as in Fig. 5B1) (see Results) revealed detectable populations of slowly rising, $\alpha 3$-nAChR-like mEPSCs in only two of eight cells and accounting for only $4 \%$ of events overall. This is similar to the incidence of slowly rising, $\alpha 3$-nAChR-like mEPSCs observed in conventional whole-cell recordings (4\%; see Results). Finally, to explore the possibility that asynchronous mEPSCs elicited by stimulation in strontium might represent only a subset of uniquantal events in the readily releasable pool, I analyzed mEPSCs recorded by exposing terminals to hypertonic solution ( $300 \mathrm{~mm}$ sucrose dissolved in saline and delivered via a pipette to the vicinity of the cell). In a sample of nine cells, with 180-500 mEPSCs analyzed per cell, mEPSC amplitude was $-27.9 \pm 3.9 \mathrm{pA}$, mEPSC rise time was $0.44 \pm 0.11 \mathrm{~ms}$, and mEPSC decay time was $2.81 \pm 1.29 \mathrm{~ms}$. The kinetics of sucrose-generated mEPSCs were not different than those obtained with strontium ( $p=0.053$ for rise time and $p=0.70$ for decay time), whereas the amplitude of mEPSCs generated by hypertonic solution was smaller than those generated in strontium $(p=0.003)$. An analysis of rise time probability density functions of these cells revealed Gaussians of slowly rising, $\alpha 3$-nAChR-like mEPSCs in only two of nine cells and accounting for only $5 \%$ of events overall. This is similar to the incidence of slowly rising, $\alpha 3$-nAChR-like mEPSCs produced asynchronously by low frequency stimulation in strontium (4\%; see Results). Thus, the characteristics of mEPSCs collected as asynchronous release events by stimulation in strontium are not altered by switching to perforated-patch recordings, and the kinetics of these mEPSCs are similar to those recorded by exposure of terminals to hypertonic solutions, which are believed to release the entire readily releasable transmitter pool (Rosenmund and Stevens, 1996).

Perforated-patch recordings were made with amphotericin B using standard methods (Horn and Marty, 1988; Rae et al., 1991) and $1.5 \mathrm{~mm}$ thin-walled borosilicate glass pipettes with initial resistances of 1.3-2.0 $\mathrm{M} \Omega$. The final series resistance in these recordings was 7-22 $\mathrm{M} \Omega$, and $60-80 \%$ series resistance compensation was used via the Axopatch 200B amplifier. Breakdown of the patch occurred rarely and was accompanied by an abrupt decrease in series resistance.

Uniquantal-evoked events were recorded in normal saline containing $2 \mathrm{mM} \mathrm{Ca}^{2+}, 1 \mathrm{mM} \mathrm{Mg}^{2+}$, and 15-40 $\mu \mathrm{M} \mathrm{Cd}^{2+}$, a nonspecific blocker of voltage-dependent calcium channels. The concentration of $\mathrm{Cd}^{2+}$ was adjusted to achieve a failure rate for transmission of $85-90 \%$, under which conditions the incidence of multiquantal events is $<8 \%$ of successes and insensitive to variations in readily releasable pool size over the range of 100-1000 (Silver, 2003). Neuromatic, implemented within Igor Pro, was used to distinguish successes from failures by generating a Gaussian fit to the distribution of responses (most of which are failures), measured as peak current recorded during the release window, by assigning as a "success" events with a response more negative than this Gaussian. Assignments were then checked manually, after which the average of the failures was subtracted from all events to produce records suitable for analysis (see Fig. 7).

Higher concentrations of $\alpha$-conotoxin-MII ( $\alpha$-CTx-MII) were required in these experiments to block $\alpha 3$-nAChRs on ciliary neurons than we used previously (Ullian et al., 1997). In the current experiments, I used $300 \mathrm{~nm} \alpha$-CTx-MII, which was sufficient to block $\sim 90 \%$ of the EPSC produced by activation of $\alpha 3$-nAChRs after an incubation of $>12$ $\mathrm{min}$. The reasons for the difference between this finding and our earlier one [in which 50 nm was sufficient to block nearly all $\alpha 3$-nAChRs (Ullian et al., 1997)] is not known. Nai et al. (2003) also report that $300 \mathrm{~nm}$ $\alpha$-CTx-MII blocked $\sim 90 \%$ of the $\alpha 3$-nAChR response to application of nicotinic agonist. The presence of a residual population (10\%) of $\alpha 3$ nAChRs not blocked by $300 \mathrm{~nm} \alpha$-CTx-MII is likely to have introduced a small error into the measurement of the properties of pharmacologically isolated $\alpha 7$-nAChR mEPSCs (see Results).

Statistical tests were made using PAST.exe (Hammer et al., 2001). Sample errors are given as SD. Samples were compared using the Student's $t$ test. The $F$ test was used to determine whether probability density functions of mEPSC parameters were better fit with the sum of $n+1$ Gaussians than with $n$ Gaussians.

\section{Results}

EPSCs evoked from ciliary ganglion neurons by low frequency stimulation of the preganglionic nerve are large $(-5.4 \pm 3.2 \mathrm{nA}$; mean $\pm \mathrm{SD} ; n=64)$ and rapid, having a rise time of $0.62 \pm 0.13$ $\mathrm{ms}$ and a decay time of $4.0 \pm 1.5 \mathrm{~ms}$ (Fig. 1). As found previously (Zhang et al., 1996; Ullian et al., 1997), $\alpha 3-n A C h R$ and $\alpha 7$ nAChR antagonists had distinct effects on EPSC amplitude and kinetics (Fig. 1). $\alpha$-CTx-MII, a snail toxin that blocks nAChRs with an $\alpha 3-\beta 2$ interface (Cartier et al., 1996), at $300 \mathrm{nM}$, reduced the peak amplitude of the EPSC by $19 \%(p=0.01)$, reduced the decay time by $43 \%$ ( $p=0.0003)$, but had no significant effect on the rise time $[p=0.67, n=6$, paired $t$ test (Figure $1 A 1, A 2$ ); $\alpha$-CTx-MII also blocks $\alpha 6$-AChRs, but the $\alpha 6$ gene is not expressed in the ciliary ganglion (Fucile et al., 1998)]. Methyllycaconitine (MLA), an $\alpha 7$-nAChR selective antagonist in the ciliary ganglion (Vijayaraghavan et al., 1992), at $50 \mathrm{~nm}$ reduced the peak amplitude of the EPSC by $82 \%$, prolonged the rise time by $270 \%$, and prolonged the decay time by $320 \%$ (Fig. 1 B1,B2) $(p<0.0001$ for all comparisons; $n=19)$. The application of both toxins to the ciliary ganglion reduced the EPSC amplitude to $<2 \%$ of its initial value (data not shown). Neither $\alpha$-CTx-MII nor MLA was readily reversible, with no significant return of EPSC amplitude over 30 min of wash.

EPSCs showed strong inward rectification (Fig. 1C), as occurs broadly for both native and expressed nAChRs [for review, see Quick and Lester (2002)]. Synaptic current reversed at $\sim 0 \mathrm{mV}$, and the amplitude of outward current at a holding potential of $+45 \mathrm{mV}$ was $\sim 5 \%$ of inward current at a holding potential of $-45 \mathrm{mV}$. By measuring the current both at the peak of the EPSC, which reflects, primarily, the contribution from $\alpha 7$-nAChRs (Fig. $1 A, B$ ), and $10 \mathrm{~ms}$ after the peak, which reflects, primarily, the contribution of $\alpha 3$-nAChRs (Fig. $1 A, B$ ), I infer that current through both channel classes rectifies to approximately the same extent (Fig. $1 D$ ). The time course of the EPSC was comparable at holding currents of $-60 \mathrm{mV}$ to $-15 \mathrm{mV}$ (Fig. $1 C$, inset), suggesting that the rate constant(s) governing channel closings are not strongly voltage dependent.

The participation of both $\alpha 7$-nAChRs and $\alpha 3$-nAChRs in generating evoked synaptic currents (Fig. 1) raises questions about the structure of the quantal building blocks of the EPSC. The partial segregation of nAChRs on the neuronal surface, with $\alpha 3$-nAChRs found at PSDs on the soma and with both $\alpha 7$ nAChRs and $\alpha 3$-nAChRs found on spines, leads one to predict that mEPSCs may be diverse. $\alpha 3$-nAChR-mediated mEPSCs, which are likely to be kinetically slow (Fig. 1) (Chen et al., 2001), would be expected from conventional release onto somatic PSDs, whereas faster mEPSCs might be expected from release onto spines, where $\alpha 7-\mathrm{nAChR}$ are located. I, therefore, explored the kinetic properties of uniquantal responses.

The frequency of spontaneously occurring mEPSCs was very low in most cells (Fig. 2A) (Martin and Pilar, 1964). Across 21 cells, the mean spontaneous mEPSC rate was $0.24 \pm 0.06 \mathrm{~Hz}$, and the median rate was $0.06 \mathrm{~Hz}$ (the difference between median and mean was due widely to one cell having a rate of $2.6 \mathrm{~Hz}$ ). To increase mEPSC frequency, I stimulated the preganglionic nerve at low frequency $(2-4 \mathrm{~Hz})$ in medium containing strontium and examined events, presumed to be uniquantal (Bain and Quastel, 1992; Abdul-Ghani et al., 1996; Bekkers and Clements, 1999), that occur asynchronously (Fig. $2 B$ ). Low frequency stimulation in strontium enhanced mEPSC rate by $\sim 50$-fold ( $p=0.005$ by paired $t$ test in a sample of 10 cells). Asynchronous mEPSCs have similar kinetic properties when recorded using conventional 

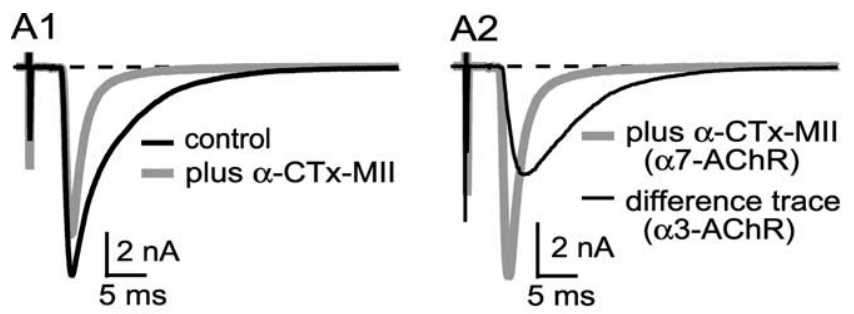

B1
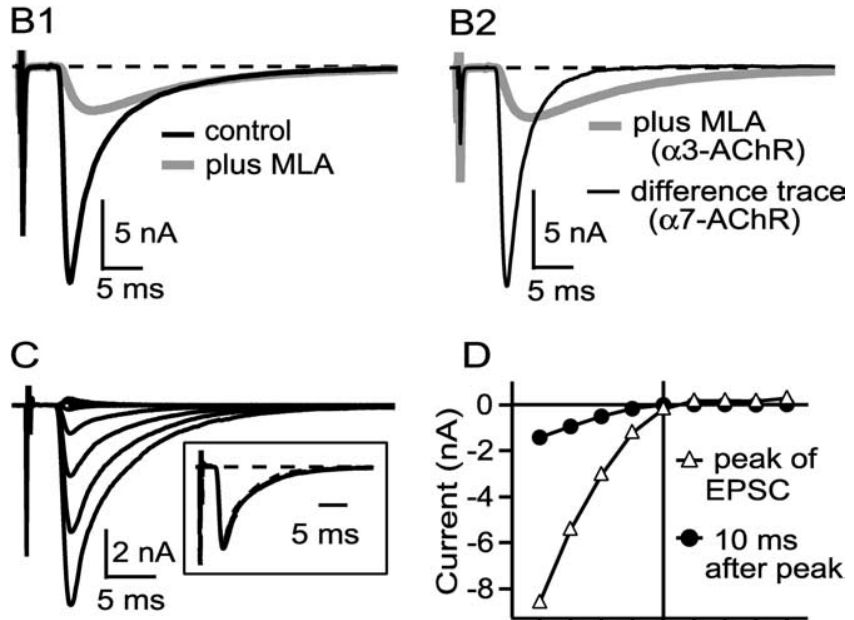

D

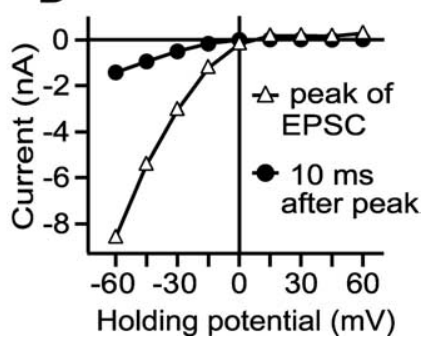

Figure 1. $A, B$, Evoked EPSCs elicited from ciliary neurons have contributions from both $\alpha 3$-nAChRs and $\alpha 7$-nAChRs. C, $\boldsymbol{D}, \alpha 3$-nAChR- and $\alpha 7$-nAChR-mediated currents show inward rectification. $\boldsymbol{A} \mathbf{1}$ and $\boldsymbol{B} 1$ show examples of EPSCs elicited by $0.03 \mathrm{~Hz}$ preganglionic stimulation before and after addition of either $300 \mathrm{~nm} \alpha$-CTx MII (AT), which blocks $\alpha 3$-nAChRs, or $50 \mathrm{~nm}$ MLA (B1), which blocks $\alpha$ 7-nAChRs. A2 reproduces the EPSC from A1 in $\alpha$-CTx MII ( $\alpha 7$-nAChR current) plus a difference curve (before minus after, representing $\alpha 3$-nAChR current), whereas $B 2$ reproduces the EPSC in $B 1$ in MLA ( $\alpha 3$-nAChR current) plus a difference curve (representing $\alpha 7$-nAChR current). $\alpha 3$-nAChR currents are slower than $\alpha 7$-nAChR currents (A2, B2). All records are the average of $3-5$ traces. ( shows an EPSC from one connection at holding potentials of $-60 \mathrm{mV}$ to $+60 \mathrm{mV}$ (15 mV increments), and $\boldsymbol{D}$ shows the current at the peak (dominated by $\alpha 7$-nAChRs) and $10 \mathrm{~ms}$ after the peak (dominated by $\alpha 3$-nAChRs) versus holding potential, uncorrected for a calculated $-5 \mathrm{mV}$ liquid junction potential. Both $\alpha 7$-nAChR- and $\alpha 3$-nAChR-mediated currents rectify to approximately the same degree. Each trace in $\mathbf{C}$ is the average of three traces collected at $0.03 \mathrm{~Hz}$. Similar results were obtained in three other cells.

whole-cell methods or perforated-patch methods (see Materials and Methods). mEPSCs produced by exposing terminals to hypertonic solutions are kinetically similar to asynchronous mEPSCs produced by stimulation in strontium (see Materials and Methods).

MEPSCs recorded from ciliary neurons are diverse in size and shape. Figure $3 A 1$ shows a sample of mEPSCs representing asynchronous release to low frequency stimulation in strontium [only the late component of each trace is visible, covering the time when traces have returned to baseline (Fig. 2B)]. Many of the mEPSCs had a rapid rise, but decay times vary. Figure $3 B 1-B 3$ shows probability density functions for amplitude, rise time, and decay time [all measurements are made on fits to mEPSCs (Fig. $3 A 2)$. All probability density functions are positively skewed and show considerable variability; the average amplitude, rise time, and decay time for mEPSCs from this cell was $-42 \pm 24 \mathrm{pA}$, $0.45 \pm 0.34 \mathrm{~ms}$, and $3.9 \pm 2.7 \mathrm{~ms}$, respectively. Across a sample of 14 cells, mean mEPSC amplitude was $-50 \pm 19 \mathrm{pA}$ (range, -24 to $-84 \mathrm{pA}$ ), mean $\mathrm{mEPSC}$ rise time was $0.36 \pm 0.08 \mathrm{~ms}$ (range, 0.24-0.50 ms), and mean mEPSC decay time was $2.6 \pm 1.2 \mathrm{~ms}$ (range, 1.5-5.9 ms). Across-cell variability in amplitude, rise
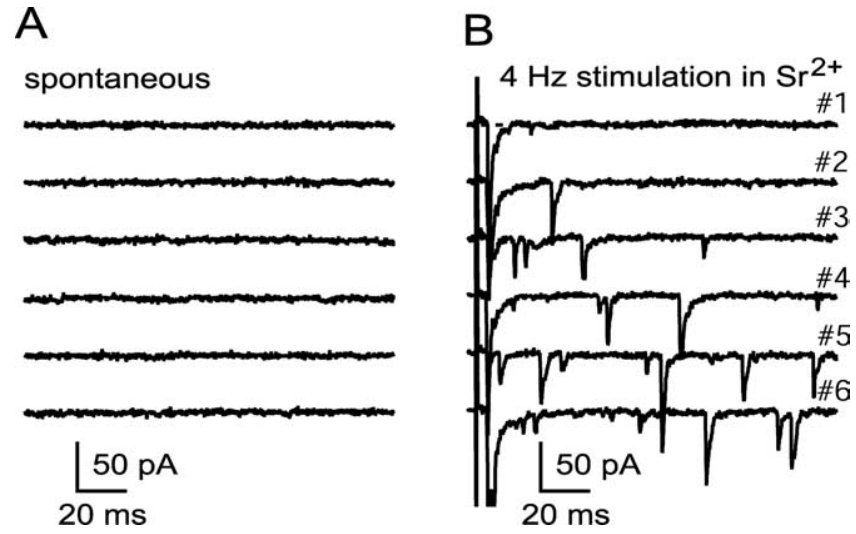

Figure 2. MEPSC frequency is low at rest and is elevated by $4 \mathrm{~Hz}$ stimulation in strontium. $A$ and $\boldsymbol{B}$ show samples of recordings at rest and during $4 \mathrm{~Hz}$ stimulation in $0.5 \mathrm{~mm} \mathrm{Ca}^{2+}, 2.5 \mathrm{~mm}$ $\mathrm{Mg}^{2+}$, and $2.0 \mathrm{~mm} \mathrm{Sr}^{2+}$.

time, and decay time was significant, and cell-to-cell comparisons often revealed significant differences in amplitude and in kinetics (the percentage of pair-wise comparisons yielding $p<$ 0.05 following ANOVA was 79,45 , and $65 \%$, for amplitude, rise time, and decay time, respectively).

Our current understanding about the location of $\alpha 7$-nAChRs and $\alpha 3$-nAChRs in relation to release sites at the calyciform synapse suggests that multiple classes of mEPSCs might exist. However, probability density functions of mEPSC amplitudes, rise times, and decay times are not obviously multimodal (Fig. 3B). Without information about the amplitude and kinetics of mEPSCs that would be produced by activation of either $\alpha 7$ nAChRs or $\alpha 3$-nAChRs alone, it is difficult to make inferences about the substructure of native populations of mEPSCs. I, therefore, examined the properties of pharmacologically isolated “ $\alpha 3$-nAChR mEPSCs" and " $\alpha 7-n A C h R$ mEPSCs" produced by blocking $\alpha 7$-nAChRs and $\alpha 3$-nAChRs, respectively.

Figure $4 A$ shows the properties of mEPSCs recorded from a cell after blocking $\alpha 3$-nAChRs with 300 nM $\alpha$-CTx-MII. Pharmacologically isolated $\alpha 7-\mathrm{nAChR}$ mEPSCs are variable in amplitude, but many are both fast rising and fast decaying (Fig. 4A1), as expected from the rapid time course of evoked EPSCs recorded after addition of $\alpha$-CTx-MII (Fig. 1). mEPSCs sampled from the cell featured in Figure $4 A$ had an amplitude of $-67 \pm 48 \mathrm{pA}$, a rise time of $0.29 \pm 0.11 \mathrm{~ms}$, and a decay time of $1.74 \pm 1.20 \mathrm{~ms}$ $(n=131)$. I will focus on the kinetics of pharmacologically isolated mEPSCs, because they will be shown to differ significantly between $\mathrm{nAChR}$ types. The probability density functions of the rise times (Fig. 4A4) and decay times (Fig. 4A5) for this cell are adequately fit with single Gaussians having modes of $0.27 \pm 0.09$ $\mathrm{ms}$ and $1.16 \pm 0.53 \mathrm{~ms}$, respectively ( $F$ test; $p>0.2$ for null hypothesis: two Gaussians are not better than one). In a sample of six cells, mean mEPSC amplitude, rise time, and decay time in $300 \mathrm{~nm} \alpha$-CTx-MII were $-34 \pm 17 \mathrm{pA}, 0.32 \pm 0.02 \mathrm{~ms}$, and $1.66 \pm 0.18 \mathrm{~ms}$, respectively. Rise time and decay time probability density functions were positively skewed and sometimes better fit by the sum of two Gaussians than by a single Gaussian. For rise times, the distributions were best fit by a single Gaussian for five of the six cells with a mode of $0.29 \pm 0.02 \mathrm{~ms}$ (in the sixth cell, the weighted average mode of the two Gaussians was also $0.29 \mathrm{~ms}$ ) For decay times, a single Gaussian sufficed for three of the cells (mode, $1.09 \pm 0.19 \mathrm{~ms}$ ) and the sum of two Gaussians for the other three cells [modes, $0.87 \pm 0.18 \mathrm{~ms}$ (44\% of events) and $1.67 \pm 0.31 \mathrm{~ms}$ ( $56 \%$ of events); weighted mode of $1.13 \pm 0.15$ 
A1
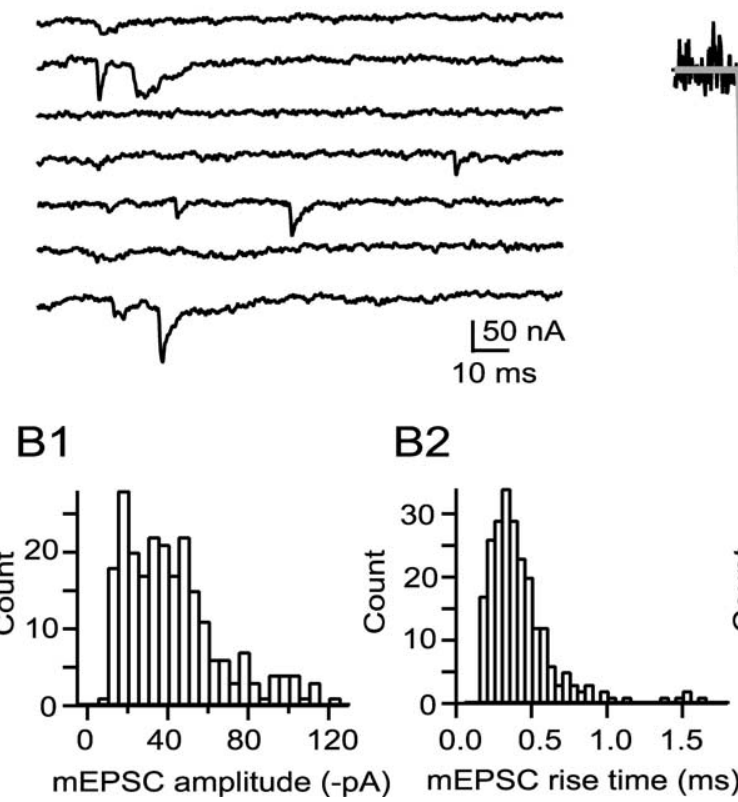

A2

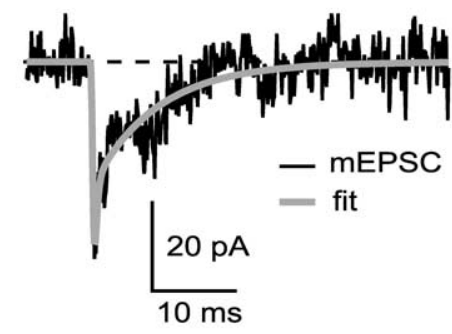

B3

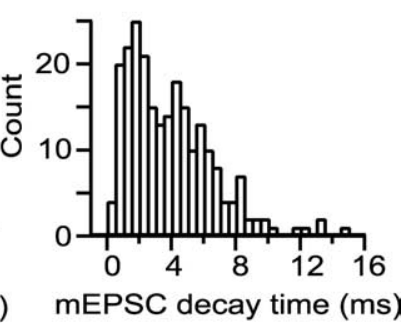

Figure 3. $m E P S C s$ are heterogeneous in amplitude, rise time, and decay time. A1 illustrates a sample of mEPSCs obtained during the second $100 \mathrm{~ms}$ of seven sequential responses after evoking EPSCs in $0.5 \mathrm{~mm} \mathrm{Ca}{ }^{2+}, 2.5 \mathrm{~mm} \mathrm{Mg}^{2+}$, and $2.0 \mathrm{~mm} \mathrm{Sr}{ }^{2+}$, by which time the baseline had returned to zero. $\mathrm{mEPSC}$ are fitted $(\boldsymbol{A 2})$, and the probability density functions of the fits displayed in $\boldsymbol{B} 1$ (amplitude), $\boldsymbol{B 2}$ (rise time), and $\boldsymbol{B} 3$ (decay time). The fastest rise time values (calculated on fits; $\boldsymbol{A 2}$ ) were in the range of $0.10-0.15 \mathrm{~ms}$, which corresponds to 2-3 data points at $20 \mathrm{kHz}$ sampling (across 14 cells, $97 \%$ of rise times were $>0.15 \mathrm{~ms}$ ). The fastest decay times across 14 cells were $0.35 \pm 0.09 \mathrm{~ms}$; thus, decay times in the fastest bin (B3; $0-0.5 \mathrm{~ms})$ are in the range of $0.35-0.5 \mathrm{~ms}$

ms, not different from the mode of "single Gaussian cells," $p=$ $0.8]$. Cells having rise time or decay time probability density functions best fit by one or by two Gaussians do not appear to be qualitatively different.

Pharmacologically isolated $\alpha 3$-nAChR mEPSCs, produced by blocking $\alpha 7$-nAChRs, are kinetically slow relative to pharmacologically isolated $\alpha 7$-nAChR mEPSCs. Figure $4 B$ shows the properties of mEPSCs recorded from a cell after blocking $\alpha 7$-nAChRs with $50 \mathrm{~nm}$ MLA. Pharmacologically isolated $\alpha 3-\mathrm{nAChR}$ mEPSCs are both slowly rising and slowly decaying (Fig. 4B1). mEPSCs recorded from this cell had an amplitude of $-32 \pm 16$ $\mathrm{pA}$, a rise time of $1.27 \pm 0.71 \mathrm{~ms}$, and a decay time of $6.7 \pm 3.4 \mathrm{~ms}$ $(n=228)$. The probability density function of rise times (Fig. $4 B 4$ ) was better fit by the sum of two Gaussians than by one ( $p=$ $0.005, F$ test), with $37 \%$ of the events having a rise time of $0.90 \pm$ $0.29 \mathrm{~ms}$ and $63 \%$ of the events having a rise time of $1.36 \pm 0.89$ ms. The probability density function of decay times was also better fit by the sum of two Gaussians (Fig. 4B5) ( $p=0.007, F$ test), with $39 \%$ of the events having a decay time of $5.2 \pm 1.7 \mathrm{~ms}$ and $61 \%$ of the events having a decay time of $7.2 \pm 3.5 \mathrm{~ms}$. Across eight cells treated with MLA, average MEPSC amplitude was $-25.3 \pm 7.4 \mathrm{pA}$, average rise time was $1.28 \pm 0.35 \mathrm{~ms}$, and average decay time was $6.7 \pm 1.5 \mathrm{~ms}$. Across six cells where I collected $>100$ mEPSCs, I found that rise time probability density functions were better fit by a single Gaussian in four instances (mode, $1.19 \pm 0.28 \mathrm{~ms}$ ) and by the sum of two Gaussians in two instances (weighted mode, $1.24 \mathrm{~ms}$, not different from single Gaussian data; $p=0.40$ ). Decay time probability density functions were best fit by single Gaussians in three instances $(6.1 \pm 2.6$ $\mathrm{ms}$ ) and by the sum of two Gaussians in the other three instances [weighted mode, $5.7 \pm 1.1 \mathrm{~ms}$, not different from single Gaussian data $(p=0.80)$ ], with no suggestion that they are qualitatively different.

The tendency of pharmacologically isolated $\alpha 7$-nAChR mEPSCs and $\alpha 3$-nAChR mEPSCs to show rise time and decay time distributions better fit with the sum of two Gaussians might reflect heterogeneity in $\alpha 7$-nAChR and $\alpha 3$-nAChR channel properties (Nai et al., 2003), but distinct subpopulations of nAChRs cannot explain the heterogeneity in mEPSC populations if they are intermixed on the cell surface, because ACh quanta would sample them both and generate mEPSCs with averaged properties. The heterogeneity of mEPSCs could be explained by diversity in the physical relationship between release sites and nAChRs, but a specific hypothesis must await additional information about the molecular environment within the synaptic cleft.

Pharmacologically isolated $\alpha 7-\mathrm{nAChR}$ mEPSCs and $\alpha 3$-nAChR mEPSCs are kinetically distinct, as shown in Figure 4C1, which displays fits to the rise-aligned average mEPSCs from the cells featured in Figure $4, A$ and $B$, and with the peak amplitudes scaled to the average across cells (the mean rise and decay times of mEPSCs from these cells were within $10 \%$ of the population means). The amplitudes of pharmacologically isolated $\alpha 7$-nAChR mEPSCs and $\alpha 3$-nAChR mEPSCs are not different ( $p=0.19$ ), whereas the rise times and decay times are highly significantly different (Fig. 4C2,4C3). Mixed mEPSCs, arising from coactivation of $\alpha 7$-nAChRs and $\alpha 3$-nAChRs, should have kinetics that are intermediate between fast $\alpha 7$-nAChR mEPSCs and slow $\alpha 3$ nAChR mEPSCs. By simulating mixed mEPSCs having variable amounts of $\alpha 7$-nAChR and $\alpha 3$-nAChR activation (Fig. 4C4), one can conclude that activation of $\alpha 7$-nAChRs should endow mixed mEPSCs with fast rise times, whereas activation of $\alpha 3-\mathrm{nAChRs}$ will tend to give mixed mEPSCs slow decay times. Thus, the best diagnostic for $\alpha 3$-nAChR mEPSCs in native mEPSC populations should be events with a slow rise time, whereas the best diagnostic for $\alpha 7$-nAChR mEPSCs should be events with a fast decay time.

To look for "pure" $\alpha 3$-nAChR mEPSCs within native populations of mEPSCs, I searched for events with a slow rise; I found these events to be rare. Figure $5 A 1$ shows examples of mEPSCs from one cell that did have a detectable population of slowly rising mEPSCs. The rise time probability density function of 316 events (Fig. 5B1) shows a skewed distribution that was best fit by the sum of three Gaussians having modes of $0.25 \mathrm{~ms}$ ( $44 \%$ of events), $0.42 \mathrm{~ms}$ ( $39 \%$ of events), and $0.86 \mathrm{~ms}$ ( $17 \%$ of events; by $F$ test three Gaussians provided a better fit than two; $p=0.02$ ). The slowest Gaussian mode $(0.86 \mathrm{~ms})$ is similar to the mode of Gaussian fits of pharmacologically isolated $\alpha 3$-nAChR mEPSCs ( $p=0.15$ by one sample $t$ test). In three other cells having a small number of slowly rising mEPSCs, a three Gaussian fit identified a population of mEPSCs with rise time mode of $0.70-0.80 \mathrm{~ms}$ (7-16\% of the events). These events, having a modal rise time of $0.79 \pm 0.07 \mathrm{~ms}(n=4$ cells $)$, are similar to those of pharmacologically isolated $\alpha 3$-nAChR mEPSCs $(1.08 \pm 0.29 \mathrm{~ms} ; n=6 ; p=$ 0.10 ), suggesting that they represent $\alpha 3$-nAChR mEPSCs. For 


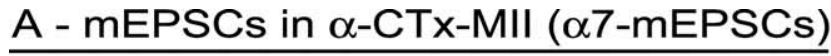

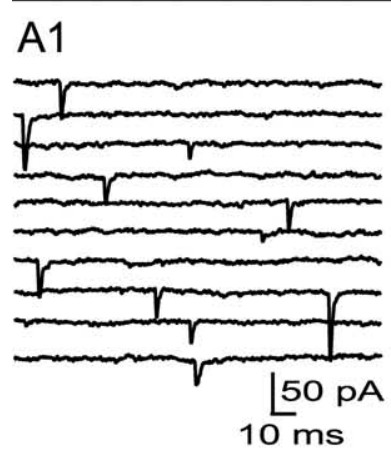

A2

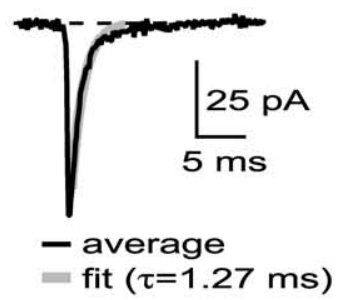

A3
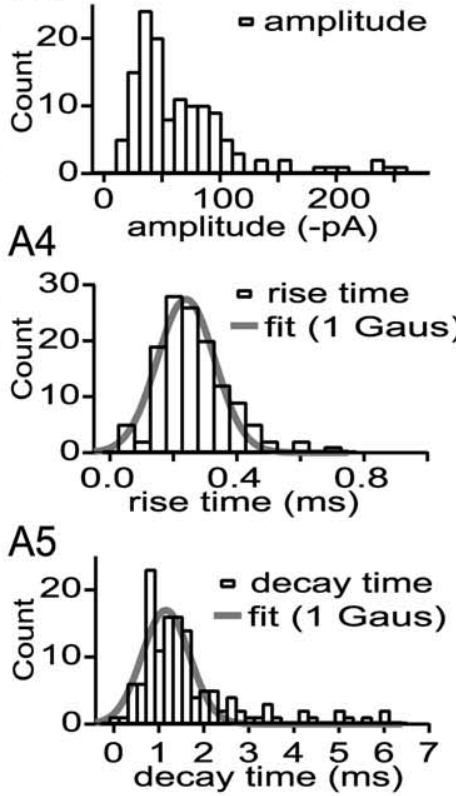

\section{C - Summary}

C1
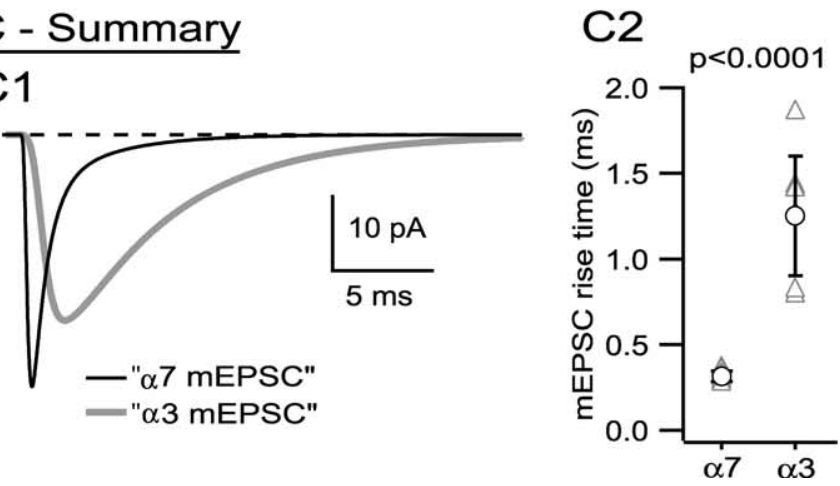

\section{B - mEPSCs in MLA ( $\alpha 3-m E P S C s)$}

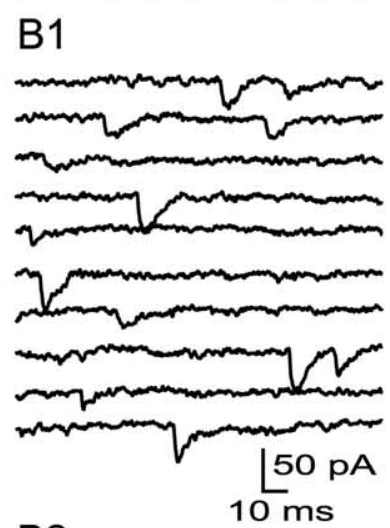

B3

B2
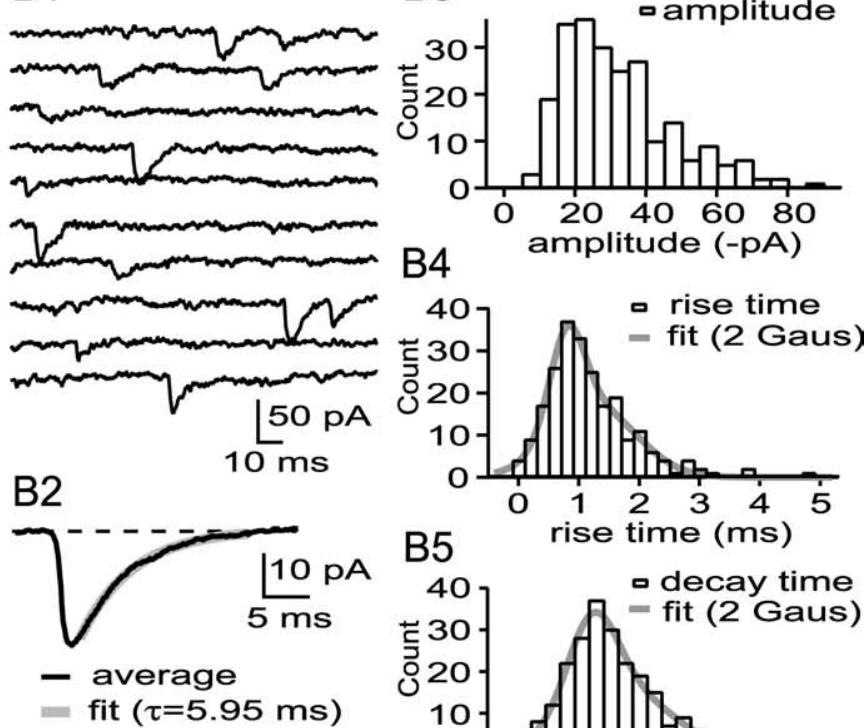

B5

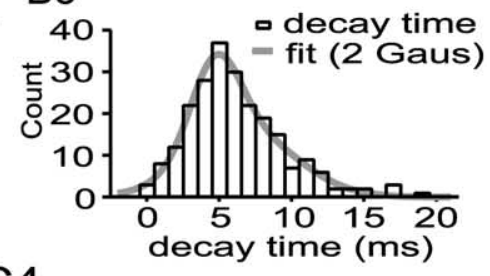

C3
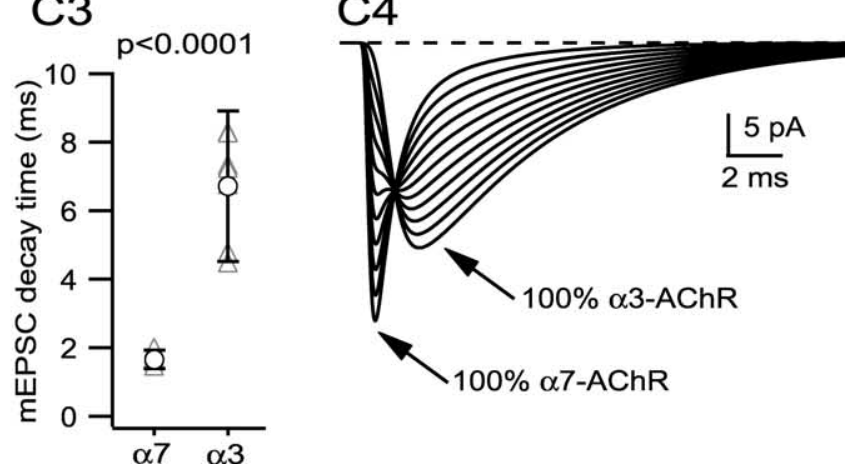

Figure 4. Pharmacologically isolated $\alpha 7$-nAChR mEPSCs and $\alpha 3$-nAChR mEPSCs are kinetically distinct. $\boldsymbol{A}$ shows data from a cell where $\alpha 7$-nAChR mEPSCs were generated pharmacologically by blocking $\alpha 3$-nAChRs; $\boldsymbol{B}$ shows data from a cell where $\alpha 3$-nAChR mEPSCs were generated by blocking $\alpha$ 7-nAChRs; $\boldsymbol{C}$ shows summary data. $\boldsymbol{A} 1$ shows a sample of mEPSCs recorded after blocking $\alpha 3$-nAChRs with $\alpha$-CTx MII (nonconsecutive traces), and A2 shows the average mEPSC (aligned on the 50\% rise), most of whose decay is well fit with an exponential having a $\tau$ of $1.27 \mathrm{~ms}$. A3-A5 show probability density functions for mEPSC amplitude, rise time, and decay time for this cell. Both the rise time and the decay time density functions are adequately fit with single Gaussians (details in Results). See legend to Figure 3 for additional information regarding binning of rise and decay time values. B1 shows a sample of mEPSCs recorded after blocking $\alpha 7$-nAChRs with MLA, and B2 shows the average mEPSC (aligned on the $50 \%$ rise), the decay of which is well fit with an exponential having a $\tau$ of $5.95 \mathrm{~ms}$. B3-B5 show probability density functions for amplitude, rise time, and decay time for this cell. Both rise time and decay time distributions show positive skewness and are better fit by the sum of two Gaussians rather than one (details in Results). See legend to Figure 3 for additional information regarding binning of rise and decay time values. C1 shows fitted mEPSCs corresponding to the average mEPSCs recorded from cells shown in parts $\boldsymbol{A}$ and $\boldsymbol{B}$ and scaled to the cell average for all experiments. Across cells, there was no difference in amplitude of pharmacologically isolated $\alpha 7$-nAChR and $\alpha 3$-nAChR mEPSCs, but there was a highly significant difference in their rise times (C2) and decay times (C3). C4 shows a series of simulated fits to mEPSCs containing varying amounts of $\alpha 7$-nAChR and $\alpha 3$-nAChR contributions (100/0\%, 90/10\%, etc.); mixed $\mathrm{mEPSCs}$ are likely to have a rapid rise, attributable to the activation of $\alpha 7$-nAChRs, and a slow decay, attributable to the activation of $\alpha 3$-nAChRs.

two of the four cells showing a population of slowly rising mEPSCs, including the one featured in Figure 5, A1 and B1, I subsequently added $\alpha$-CTx-MII to block $\alpha 3$-nAChRs and found that it abolished nearly all mEPSCs with rise times $>0.5 \mathrm{~ms}$ (Fig. 5B2); mEPSCs after addition of $\alpha$-CTx-MII had rise times similar to that of the fastest Gaussian of the triple Gaussian fit (Fig. 5B2). For the remaining two cells having a population of slowly rising mEPSCs, I subsequently added MLA to block $\alpha 7$-nAChRs, which resulted in rise time probability density functions with single Gaussian fits having modal values similar to the slow mode of the triple Gaussian fits before MLA ("before and after" values were 0.80 and $1.07 \mathrm{~ms}$ for one cell and 0.71 and $0.70 \mathrm{~ms}$ for the other). This confirms that the small subpopulations of slowly rising mEPSCs detected in native mEPSC populations of some cells have the characteristics of pharmacologically isolated $\alpha 3-\mathrm{nAChR}$ mEPSCs.

Most cells did not display a detectable population of $\alpha 3$ nAChR mEPSCs; rise times from one such cell (Fig. 5C1) were fit with a single Gaussian of $0.24 \pm 0.16 \mathrm{~ms}$ (compare with Fig. 5B1). The suitability of a single Gaussian fit for this cell's mEPSC rise time probability density function does not imply that all mEPSCs in this cell are pure $\alpha 7-\mathrm{nAChR}$ events, however, because mixed mEPSCs may have fast rise times (Fig. 4C4). A role for $\alpha 3$ nAChRs in the production of some mEPSCs in this cell was revealed by blocking $\alpha 7$-nAChRs with MLA. A scatter plot of mEPSC amplitude versus rise time for this cell (Fig. 5C2) shows a kinetically fast "fingerprint" of events with a broad amplitude distribution (closed circles) in control conditions and a kineti- 
A1

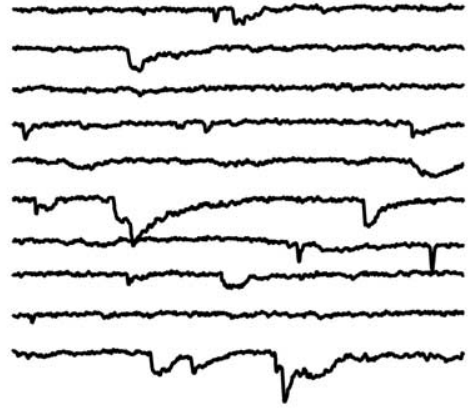

control

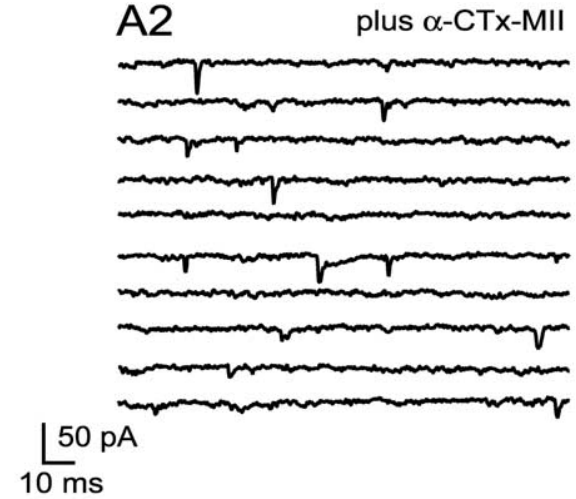

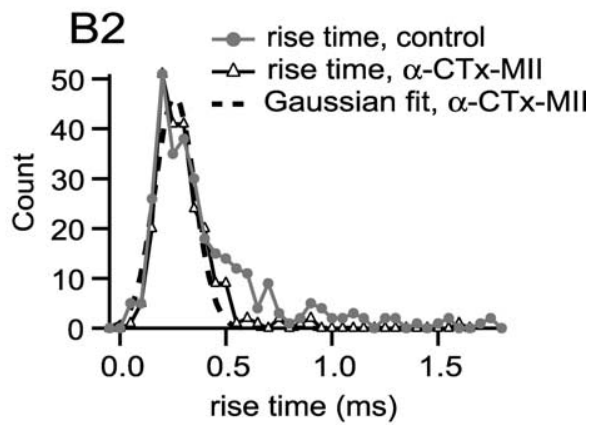

$\mathrm{C} 2$

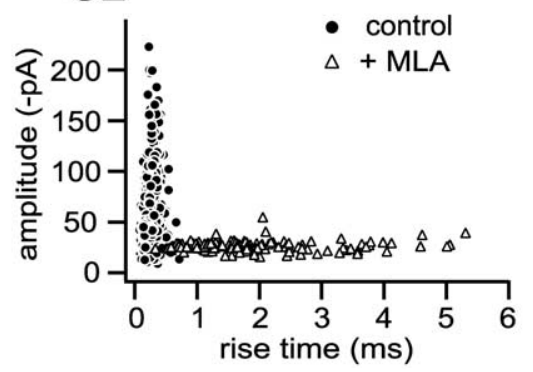

Figure 5. $\mathrm{mEPSC}$ arising from activation of $\alpha 3-\mathrm{nAChRs}$ are rare. $\boldsymbol{A} 1$ shows examples of $\mathrm{mEPSC}$ recorded from a cell having a detectable population of slowly rising events ( 10 sequential responses). The probability density function of events can be fit with the sum of three Gaussians $(\boldsymbol{B 1})$, the slowest mode of which $(0.86 \mathrm{~ms})$ is comparable with that of pharmacologically isolated $\alpha 3-n A C h R$ mEPSCs. Blocking $\alpha 3-n A C h R s$ in this cell (A2) eliminated this population as well as a population of events having an intermediate rise $(0.42 \mathrm{~ms})$ to produce a distribution of rise times adequately fit by a single fast Gaussian having a mode of $0.28 \mathrm{~ms}$ (B2), similar to the fastest rise time mode before $\alpha$-CTx MII $(0.25 \mathrm{~ms} ; \boldsymbol{B} 1)$. Across six cells, blocking $\alpha 3$-nAChRs reduced mEPSC amplitude by $14 \%$ ( $p=0.05$ by paired $t$ test), reduced mEPSC rise time by $22 \%(p=0.007$ ), and reduced mEPSC decay time by $43 \%(p=0.03)$. Only four cells of fourteen had rise time probability density functions with a detectable population of slowly rising events (as in B1). C1 shows another cell with a rise time probability density function fit with a single Gaussian of $0.24 \mathrm{~ms}$ ( $n=577 ; p=0.99$ by $F$ test); there is no suggestion of a population of $\alpha 3-n A C h R$ mEPSCs (compare with $B 1$ ). An amplitude versus rise time fingerprint of this cell before and after addition of MLA to block $\alpha 7$-nAChRs (C2) graphically illustrates that kinetically slow $\alpha 3-n A C h R m E P S C s$, with a broad spectrum of rise times and a relatively narrow spectrum of amplitudes (open triangles), are not detected in the native population (closed circles). Across eight cells, blocking $\alpha 7-n A C h R s$ reduced detectable mEPSC amplitude by 53\% ( $p=0.0008$ by paired $t$ test), increased mEPSC rise time by $431 \%$ ( $p=0.0002$ ), and increased mEPSC decay time by $351 \%$ ( $p=0.0003$ ). See legend to Figure 3 for additional information regarding binning of rise time values.

cally slow and dispersed fingerprint of events with narrower amplitude distribution after blocking $\alpha 7$-nAChRs (open triangles). There is little overlap between the two fingerprints, meaning that there are virtually no $\alpha 3$-nAChR-like events in the native population. Thus, the kinetically slow events recorded after addition of MLA were, before addition of the antagonist, mixed mEPSCs whose amplitude was reduced and whose time course was slowed by blocking $\alpha 7$-nAChRs. The overall incidence within native mEPSC populations of slowly rising mEPSCs characteristic of $\alpha 3$-nAChR mEPSCs is small; these events were detected in only four of fourteen cells, and the overall incidence of these events across the 14 cell sample was $4 \%$. The failure to find significant numbers of $\alpha 3$-nAChR mEPSCs in native mEPSC populations is surprising, because $\alpha 3$-nAChRs are the only nAChRs thought to be clustered at PSDs.

To look for pure $\alpha 7-\mathrm{nAChR}$ mEPSCs in native mEPSC populations, I searched for populations of events having a rapid decay. All 14 cells showed mEPSC decay time probability density functions having populations of events with rapid decay times; one example is shown in Figure $6 \mathrm{A1}$. The probability density function of decay times for this cell was best fit by the sum of two Gaussians having decay times of $1.17 \pm 0.34 \mathrm{~ms}$ ( $31 \%$ of events) and $2.13 \pm 0.88 \mathrm{~ms}$ (69\% of events) (Fig. 6B1). Overall, double Gaussian fits adequately described decay time probability density functions in 11 of 14 cells ( $F$ test; $p<0.05$ ), with a fast population of events having a decay time of $1.02 \pm 0.23 \mathrm{~ms}$ (26\% of events) and a slow population of events having a decay time of $2.89 \pm 1.20 \mathrm{~ms}$ (74\% of events). The fast-decaying events in these 11 cells were similar to the average modal decay times recorded for pharmacologically isolated $\alpha 7-\mathrm{nAChR}$ mEPSCs $(1.22 \pm 0.17 \mathrm{~ms} ; p=0.08)$, which suggests that they represent mEPSCs produced by activation of $\alpha 7$-nAChRs only (in the remaining three cells decay times were adequately fit with a single Gaussian having a mode of $1.31 \pm 0.26 \mathrm{~ms}$, which is similar to the fast mode of decay for the remaining 11 cells, $p=0.08$; all mEPSCs in these cells are kinetically similar to pharmacologically isolated $\alpha 7-\mathrm{nAChR}$ mEPSCs). It is reasonable to hypothesize that the slowly decaying events (decay time of $\sim 3 \mathrm{~ms}$ ) are mixed $(\alpha 7-\mathrm{nAChR}$ plus $\alpha 3$-nAChR mEPSCs. If so, then blocking $\alpha 3$-nAChRs should collapse the slower Gaussian into the faster one. In all six cells where I subsequently added $\alpha$-CTx MII to block $\alpha 3$ nAChRs, the effect was as predicted, although in some instances the remaining $\alpha 7$-nAChR mEPSCs were best described by the sum of two Gaussians rather than one. Blocking $\alpha 3-n A C h R s$ in the cell featured in Figure $6 A 1$ produced briefer mEPSCs (Fig. 6A2) and converted a two Gaussian fit into a single Gaussian fit with a decay time mode characteristic of $\alpha 7$-nAChRs (Fig. 6 B2) (fast mode before $\alpha$-CTx-MII, $1.17 \mathrm{~ms}$; single mode in $\alpha$-CTx MII, $1.20 \mathrm{~ms}$ ). Similar results were obtained in a second cell (fast mode before $\alpha$-CTx-MII, $1.16 \mathrm{~ms}$; single mode in $\alpha$-CTx MII, $0.95 \mathrm{~ms})$. In the remaining four cells, the decay time probability density functions after $\alpha$-CTx MII were fit by the sum of two Gaussian with fast modes (Fig. 6C2). In these cells, the mode of the fast population of events in control conditions was not altered by $\alpha$-CTx-MII (from $0.98 \pm 0.15 \mathrm{~ms}$ to $0.88 \pm 0.15 \mathrm{~ms}$; 
$p=0.47$ by paired $t$ test), whereas the mode of the slow population of events was altered (from $2.59 \pm 0.19 \mathrm{~ms}$ to $1.75 \pm$ $0.29 \mathrm{~ms} ; p=0.04)$. This suggests that the rapidly decaying population in control conditions represents $\quad \alpha 7$-nAChR mEPSCs, whereas the slowly decaying population represents mixed mEPSCs.

The failure to detect significant numbers of kinetically slow mEPSCs, attributable to activation solely of $\alpha 3$-nAChRs, is surprising given the presence of many synaptic contacts on the soma, where only $\alpha 3$ nAChRs are thought to be clustered. An alternative approach to collecting uniquantal responses is to examine synchronous release when the probability of release is very low (Silver, 2003); might such events contain a higher incidence of slowly rising responses? I collected populations of evoked uniquantal events in six cells and compared them with asynchronous mEPSCs collected from the same cells by low frequency stimulation in strontium. Evoked uniquantal events were collected in $2 \mathrm{mM} \mathrm{Ca}^{2+}$ and $1 \mathrm{mM} \mathrm{Mg}^{2+}$ and with sufficient cadmium $(15-40 \mu \mathrm{M})$ to produce a failure rate of $\sim 85 \%$ or higher, under which conditions the expected incidence of multiquantal events will be low (Silver, 2003). For the cell illustrated in Figure 7, the EPSC in normal saline was approximately $-4 \mathrm{nA}$ in size (Fig. 7A1, inset shows an enlarged image of the capacitative artifact that marks the arrival of the presynaptic action potential in the terminal). After adding $30 \mu \mathrm{M}$ cadmium, many responses appeared to be failures (Fig. $7 A 2$ ), and successes are superimposed on the decay phase of the presynaptic capacitative artifact (Fig. 7A2, arrow). Figure 7A3 (top) shows 25 consecutive responses, consisting of four successes and 21 failures, along with the average trace of all failures (in gray). The time course of successes can be analyzed more readily after subtraction of the average of the failures (Fig. 7A3, bottom). Subsequently, I washed cadmium from the recording chamber, perfused the ganglion with strontiumcontaining saline, and collected asynchronous mEPSCs during 2-4 Hz stimulation (Fig. 7B) (showing 10 superimposed traces). Figure $7 C$ shows that evoked uniquantal responses and mEPSCs collected in strontium were similar in amplitude, rise time, and decay time. These results failed to reveal a significant population of slow, $\alpha 3$-nAChR-like responses expected from acetylcholine release at synaptic contacts on the cell body of ciliary neurons.

$\alpha 3$-nAChR-like mEPSCs are expected to be kinetically slow, and if they are small, they may be difficult to detect. If these events had escaped detection upon analysis of currents produced by synchronous release at low probability (Fig. 7A2,A3), I might expect to find evidence of a slow inward current among responses
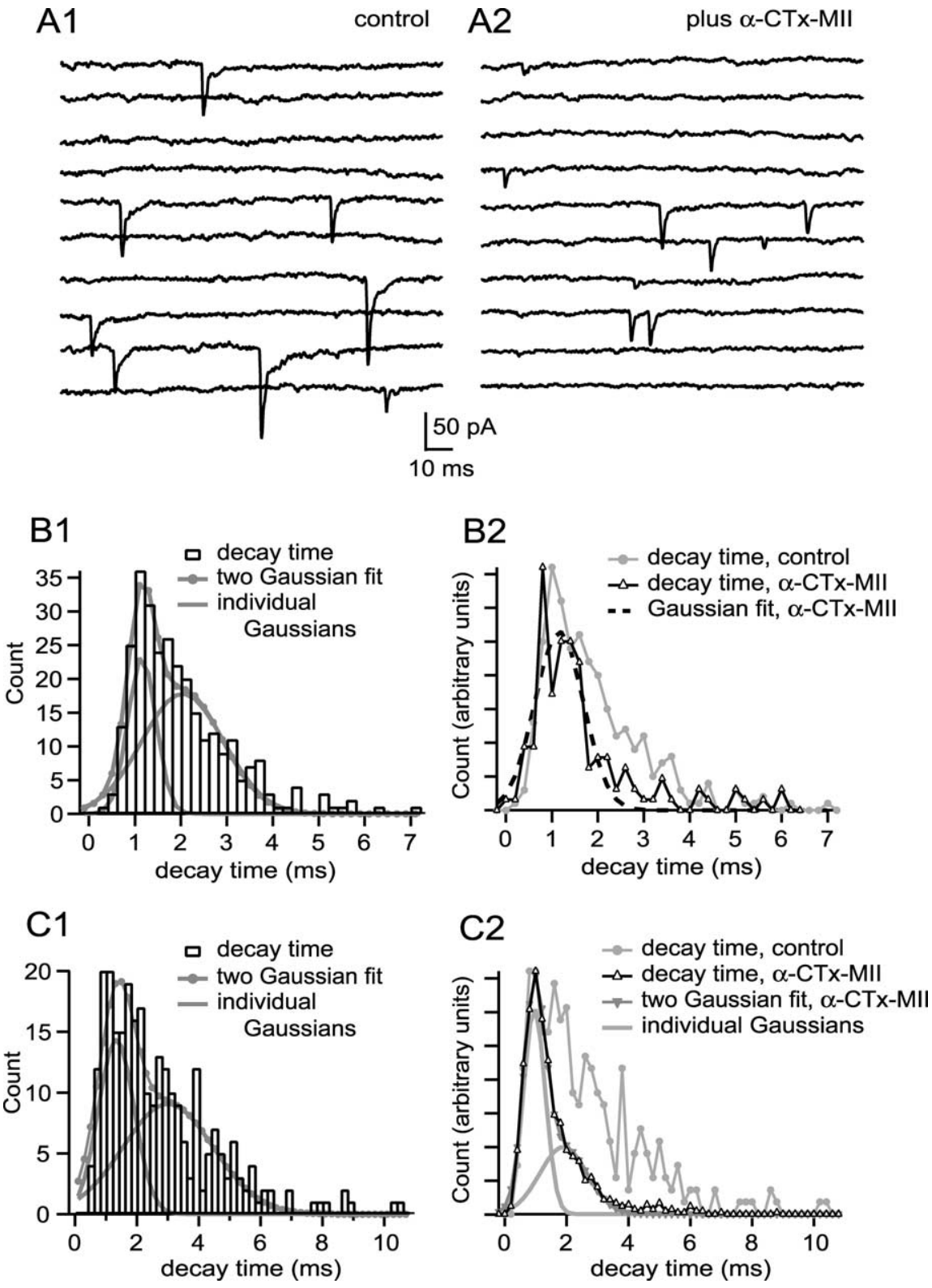

Figure 6. mEPSC populations with a rapid decay time, characteristic of pharmacologically isolated $\alpha 7-n A C h R$ mEPSCs, are common. $\boldsymbol{A} 1$ shows examples of mEPSCs recorded from a cell having fast rising mEPSCs with variable decay (10 sequential Gaussians, with modes of 1.17 and $2.13 \mathrm{~ms}$. Addition of $\alpha$-CTx MII to block $\alpha 3$-nAChRs (examples in A2; 10 sequential responses) converted the probability density function into one best fit by a single Gaussian with a mode of $1.26 \mathrm{~ms}$ (B2). C1 shows a decay time probability distribution function for a different cell that was fit with two Gaussians having modes of 1.32 and 2.98 ms. Addition of $\alpha$-CTx MII to this cell yielded, again, a two Gaussian population, with modes of 0.95 and $1.95 \mathrm{~ms}(\mathbf{C 2})$. The mode of the fast Gaussian was not altered by $\alpha$-CTx-MIl, suggesting that the fast-decaying events are produced by activation solely of $\alpha 7-n A C h R s$. See legend to Figure 3 for additional information regarding binning of decay time values.

recorded as failures. The average of failures in Figure $7 A 3$ (top, gray trace) which represents an average of 484 responses, shows no evidence of harboring a population of slow events; the trace relaxes to baseline following the presynaptic capacitative artifact. Over a 10 ms window beginning with the shortest latency of successes, the mean amplitude of failures for this cell was $-0.6 \mathrm{pA}$ (the mean is less than zero because part of the "tail" of the presynaptic capacitative artifact is included in the $10 \mathrm{~ms}$ window). Over six cells, the mean of the failures was $-1.0 \pm 1.9 \mathrm{pA}$ over this $10 \mathrm{~ms}$ window (not different from zero; one sample $t$ test; $p=$ $0.26)$. If $10 \%$ of the failures had the time course of a pharmaco- 

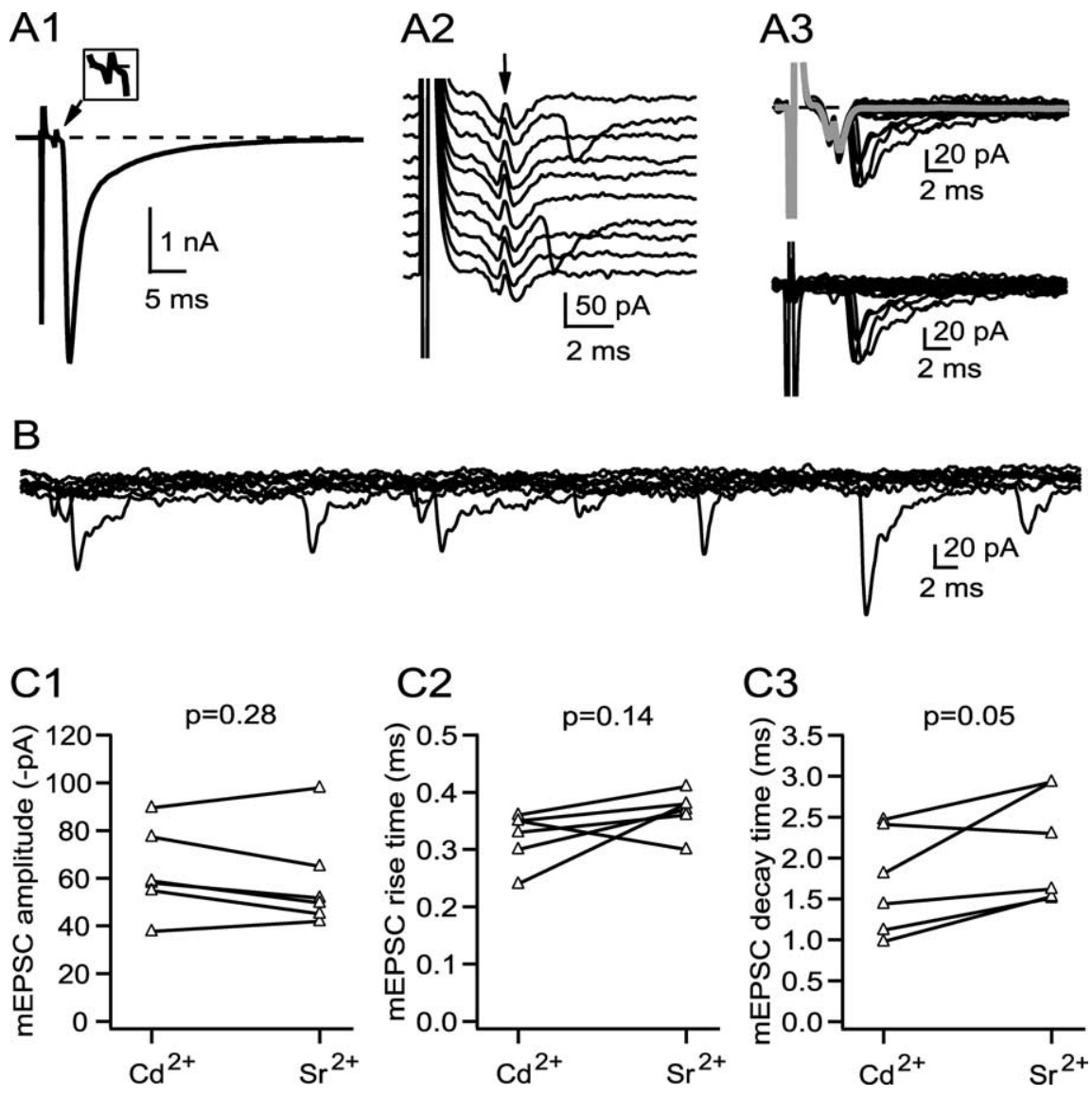

Figure 7. The properties of uniquantal responses elicited synchronously (cadmium) or asynchronously (strontium) are similar. $A \mathbf{1}$ and $\mathbf{A 2}$ illustrate EPSCs before and after blocking a majority of the calcium channels with cadmium. After cadmium, most trials result in failures ( $\boldsymbol{A} \mathbf{2}$; arrow marks the capacitative artifact that accompanies the arrival of the action potential in the presynaptic calyciform terminal). $\mathbf{A}$ (top) shows a set of 25 sequential responses ( 4 successes, 21 failures) superimposed and accompanied by the average of all failures (gray trace), and $\boldsymbol{A} \mathbf{3}$ (bottom) shows these same 25 responses after subtraction of the failures trace. The successes were compared with asynchronous mEPSCs recorded in the same cell (B; 10 superimposed traces shown). $\mathbf{C}$ - $\mathbf{C} 3$ compare amplitude, rise time, and decay time across six cells for the two populations, which were not statistically different.

logically isolated $\alpha 3$-nAChR mEPSC (Fig. 4B2) and a peak amplitude at the threshold of detection (7-10 pA), the mean failures trace would have had the shape of a slow inward synaptic current and would have been distinguishable from the observed average of failures (data not shown). Because none of the failures traces across six cells showed signs of a small inward current, I conclude that if the "missing" $\alpha 3-\mathrm{nAChR}$ mEPSCs are as numerous as mEPSCs accompanied by $\alpha$-nAChR activation, then their amplitude is likely to be well below the limit of detection.

\section{Discussion}

All ciliary neurons I studied had native mEPSC populations with fast kinetics comparable with those of pharmacologically isolated $\alpha 7$-nAChR mEPSCs. Most cells also had large populations of mEPSCs with kinetic properties indicative of the coactivation of both $\alpha 7$-nAChRs and $\alpha 3$-nAChRs. The combination of $\alpha 7$ nAChR-dominant mEPSCs $(\sim 25 \%$ of events $)$ and mixed $\alpha 7$ nAChR- $\alpha 3$-nAChR mEPSCs ( $\sim 75 \%$ of events) account for most uniquantal responses in ciliary neurons. In only four of fourteen cells did I encounter detectable numbers of mEPSCs with slow rise time, characteristic of pure $\alpha 3-\mathrm{nAChR}$ mEPSCs, and even in these four cells, the fraction of events was only $12 \%$, on average. Overall, $\sim 5 \%$ of mEPSCs have the properties expected of activation solely of $\alpha 3$-nAChRs, and this same incidence was observed for experiments using perforated-patch methodology and for experiments in which mEPSCs were elicited using hypertonic solutions (see Materials and Methods). The fact that $>95 \%$ of mEPSCs are produced by activation, in whole or in part, of $\alpha 7$-nAChRs suggests that nearly all of the detectable quantal events occur at somatic spines, where $\alpha 7$-nAChRs are concentrated (Jacob and Berg, 1983; Loring et al., 1985; Horch and Sargent, 1995; Williams et al., 1998; Shoop et al., 1999). $\alpha 7$-nAChRs are distributed widely on spines (Shoop et al., 1999), and whereas spines have PSDs, the majority of the spine membrane is extrasynaptic. This raises the possibility that activation of $\alpha 7-\mathrm{nAChRs}$ occurs via nontraditional mechanisms: either by spillover, by ectopic release, or both. The rapid rise time of mEPSCs argues that spillover is not likely to explain the results, and the MCell modeling work of Coggan et al. (2005) points toward ectopic release as the principal mechanism. However, without additional information specifically about whether $\alpha 7$-nAChRs are excluded from PSDs on spines (Williams et al., 1998) or about whether their presence at the edges of the PSD on spines could explain the rapid rise time of mEPSCs, it is not possible to conclude simply from the dominance of $\alpha 7$-nAChR receptors in producing quantal responses, reported here, that release at this embryonic synapse is ectopic.

The failure to detect $\alpha 3$-nAChRmediated mEPSCs in native mEPSC populations suggests that at this synapse ionotropic receptors concentrated at PSDs do not play a significant role in fast synaptic transmission. A large majority of PSDs on the surface of ciliary neurons are located on the soma (Nguyen and Sargent, 2002). It is unlikely that synaptic contacts on the soma are presynaptically silent, because synaptic vesicles are recycled at these sites, and at active zones on spines, in a stimulation- and calcium-dependent manner (Nguyen and Sargent, 2002). Rather, it seems more likely that responses to release at these site are too small to detect using the current technology $(<7-10 \mathrm{pA})$, perhaps because the density of $\alpha 3$-nAChRs is low (Loring and Zigmond, 1987) and/or because their $P_{\text {open }}$ is small (Nai et al., 2003). I do detect activation of $\alpha 3$-nAChRs, but only in the context of release that concomitantly activates $\alpha 7$-nAChRs and that is presumed to occur at spines. I conclude that acetylcholine release onto spines opens more $\alpha 3$-nAChR channels than does release onto the soma. If I assume that the same $\alpha 3$-nAChRs are clustered at the PSDs on spines as on somatic PSDs, then these clustered $\alpha 3$-nAChRs cannot account for $\alpha 3$-nAChR channel activation on spines. Rather, I suggest that the $\alpha 3$-nAChRs that respond to ACh release onto spines are located extrasynaptically (Horch and Sargent, 1995; Shoop et al., 1999) and that they are functionally distinct from those clustered at PSDs. At least two classes of $\alpha 3$-nAChRs are expressed by ciliary ganglion cells: each contains $\alpha 3, \alpha 5$, and $\beta 4$ subunits, and one contains, in addition, the $\beta 2$ subunit (Conroy 
et al., 1992; Vernallis et al., 1993). Based on the sensitivity of nAChRs on ciliary neurons to $\alpha$-CTx-MII, which is expected to block nAChRs with an $\alpha 3-\beta 2$ interface (Cartier et al., 1996), and to $\alpha$-CTx-Au1B, which is expected to block nAChRs with an $\alpha 3-\beta 4$ interface (Luo et al., 1998), Nai et al. (2003) concluded that the $\beta 2$-containing subset of $\alpha 3$-nAChRs accounts for most of the channel openings elicited from acutely isolated neurons by application of agonist. The putative "silent" $\alpha 3-\mathrm{nAChR}$ class lacking the $\beta 2$ subunit may be clustered at PSDs, whereas the $\alpha 3$-nAChRs containing the $\beta 2$ subunit may be distributed extrasynaptically on the spine, where they would colocalize with $\alpha 7$ nAChRs (Horch and Sargent, 1995).

My conclusion regarding the role of $\alpha 3$-nAChRs clustered at PSDs on the soma is based on the expectation that mixed mEPSCs, having contribution from both $\alpha 7$-nAChRs and $\alpha 3$ $n A C h R s$, arise from release onto spines, where the density of $\alpha 7$-nAChRs is high, and not onto the soma, where the density of $\alpha 7$-nAChRs is low (Jacob and Berg, 1983; Horch and Sargent, 1995; Williams et al., 1998; Shoop et al., 1999; but see also Loring et al., 1985). It is useful to consider whether $\alpha 7$-nAChRs on the soma, while present at low density, could nonetheless explain the mixed mEPSCs I observe, and I, therefore, simulated the possible effects of ACh release at somatic active zones on $\alpha 7-\mathrm{nAChRs}$. This approach requires knowing the distribution of $\alpha 7-\mathrm{nAChRs}$ at and near PSDs on the soma as well as the kinetic properties of $\alpha 7$-nAChRs. The number of $\alpha$-bungarotoxin-binding sites on the surface of ciliary neuron cell bodies is estimated to be 2.4 million/cell (McNerney et al., 2000). The number of $\alpha$-bungarotoxin-binding sites per $\alpha 7-\mathrm{nAChR}$ in this system is not known and could vary between one (Chen and Patrick, 1997) and five (Bourne et al., 2005). If I take three as a compromise, and if I assume that the density of $\alpha 7$-nAChRs is 10 times larger on spines than on the soma, as found by Shoop et al. (1999), then I calculate that the average density of $\alpha 7$-nAChRs is $\sim 500 / \mu \mathrm{m}^{2}$ on the spines and $50 / \mu \mathrm{m}^{2}$ on the soma. The number of $\alpha 7$-nAChRs that might be available to respond to a single quantum of ACh will be limited by the distance between release site and receptor, given the fast kinetics of $\alpha 7$-nAChR mEPSCs (Fig. $4 A$ ); if I assume 5000 acetylcholine molecules per quantum, a synaptic cleft height of $20 \mathrm{~nm}$, and a diffusion coefficient for acetylcholine of $0.21 \mathrm{~mm}^{2} \mathrm{~ms}^{-1}$ (Coggan et al., 2005), and if I use the twodimensional disk diffusion model (Barbour and Häusser, 1997), I calculate that $\alpha 7$-nAChRs activated by a quantum of ACh must lie within $0.75 \mu \mathrm{m}$ of the release site, because, otherwise, the predicted rise time of mEPSCs would be greater than the measured rise time of $\alpha 7-\mathrm{nAChR}$ mEPSCs reported here (10-90\% rise, $0.32 \pm 0.02 \mathrm{~ms}$ ). Approximately $100 \alpha 7$-nAChRs would be available to bind ACh released at the center of a disk of radius 0.75 $\mu \mathrm{m}$; to determine if this number of $\alpha 7$-nAChRs could support the observed contribution of $\alpha 7$-nAChRs to mixed mEPSCs, I implemented the kinetic model developed for chicken $\alpha 7$ nAChRs (McNerney et al., 2000; Coggan et al., 2005) in Channel$\mathrm{Lab}$ and found that the release of $5000 \mathrm{ACh}$ molecules would be expected to produce an mEPSC of only $2.5 \mathrm{pA}$ in size, which is 3-4-fold smaller than the limit of detection. The presence of acetylcholinesterase within the synaptic cleft (OlivieriSangiacomo et al., 1983), which I have ignored in my calculations, will make it even less likely that somatic release of ACh would produce detectable activation of $\alpha 7$-nAChRs there. If my assumptions are incorrect or if the kinetic model is flawed and it were possible to detect $\alpha 7-\mathrm{nAChR}$ activation by release onto somatic PSDs, then I would expect to see two populations of pharmacologically isolated $\alpha 7$-nAChR mEPSCs, produced by release onto the soma and release onto spines, with mean amplitudes differing by a factor of 10, and I do not (Fig. 4A3). Thus, I conclude that release onto somatic PSDs does not activate a sufficient number of $\alpha 7$-nAChRs to produce detectable current.

In conclusion, my results suggest that rapid synaptic transmission onto ciliary neurons in the embryonic ciliary ganglion occurs without meaningful participation from AChRs clustered at PSDs. This is an unorthodox design for a synapse, but it should be recalled that at embryonic day $14-15$, this calyciform synapse is in the midst of a developmental transformation; soon it will acquire a mixed electrical and chemical mechanism of transmission, and it will eventually break up into separate synaptic boutons (Landmesser and Pilar, 1972). Thus, the design of the E15 synapse, while effective (Chang and Berg, 1999), is not the version on which selective pressure might have been exerted. The apparent failure of these receptors to generate measurable synaptic currents does not necessarily mean that they are functionally silent; they may be important developmentally. They may also be subject to modification in situ (Margiotta et al., 1987), perhaps via specific patterns of activation (Chang and Berg, 2001), that would allow them to contribute to synaptic currents.

\section{References}

Abdul-Ghani MA, Valiante TA, Pennefather PS (1996) $\mathrm{Sr}^{2+}$ and quantal events at excitatory synapses between mouse hippocampal neurons in culture. J Physiol 495:113-125.

Bain AI, Quastel DM (1992) Quantal transmitter release mediated by strontium at the mouse motor nerve terminal. J Physiol 450:63-87.

Barbour B, Häusser M (1997) Intersynaptic diffusion of neurotransmitter. Trends Neurosci 20:377-384.

Bekkers JM, Clements JD (1999) Quantal amplitude and quantal variance of strontium-induced asynchronous EPSCs in rat dentate granule neurons. J Physiol 516:227-248.

Bourne Y, Talley TT, Hansen SB, Taylor P, Marchot P (2005) Crystal structure of a Cbtx-AChBP complex reveals essential interactions between snake alpha-neurotoxins and nicotinic receptors. EMBO J 24:1512-1522.

Cartier GE, Yoshikami D, Gray WR, Luo S, Olivera BM, McIntosh JM (1996) A new alpha-conotoxin which targets $\alpha 3 \beta 2$ nicotinic acetylcholine receptors. J Biol Chem 271:7522-7528.

Chang KT, Berg DK (1999) Nicotinic acetylcholine receptors containing $\alpha 7$ subunits are required for reliable synaptic transmission in situ. J Neurosci 19:3701-3710.

Chang KT, Berg DK (2001) Voltage-gated channels block nicotinic regulation of CREB phosphorylation and gene expression in neurons. Neuron 32:855-865.

Chen D, Patrick JW (1997) The $\alpha$-bungarotoxin-binding nicotinic acetylcholine receptor from rat brain contains only the $\alpha 7$ subunit. J Biol Chem 272:24024-24029.

Chen M, Pugh PC, Margiotta JF (2001) Nicotinic synapses formed between chick ciliary ganglion neurons in culture resemble those present on the neurons in vivo. J Neurobiol 47:265-279.

Coggan JS, Paysan J, Conroy WG, Berg DK (1997) Direct recording of nicotinic responses in presynaptic nerve terminals. J Neurosci 17:5798-5806.

Coggan JS, Bartol TM, Esquenazi E, Stiles JR, Lamont S, Martone ME, Berg DK, Ellisman MH, Sejnowski TJ (2005) Evidence for ectopic neurotransmission at a neuronal synapse. Science 309:446-451.

Conroy WG, Berg DK (1995) Neurons can maintain multiple classes of nicotinic acetylcholine receptors distinguished by different subunit compositions. J Biol Chem 270:4424-4431.

Conroy WG, Vernallis AB, Berg DK (1992) The $\alpha 5$ gene product assembles with multiple acetylcholine receptor subunits to form distinctive receptor subtypes in brain. Neuron 9:679-691.

Dani JA, Bertrand D (2007) Nicotinic acetylcholine receptors and nicotinic cholinergic mechanisms of the central nervous system. Annu Rev Pharmacol Toxicol 47:699-729.

Dryer SE (1994) Functional development of the parasympathetic neurons of the avian ciliary ganglion: a classic model system for the study of neuronal differentiation and development. Prog Neurobiol 43:281-322. 
Forsythe ID (1994) Direct patch recording from identified presynaptic terminals mediating glutamatergic EPSCs in the rat CNS, in vitro. J Physiol 479:381-387.

Fucile S, Matter JM, Erkman L, Ragozzino D, Barabino B, Grassi F, Alemà S, Ballivet M, Eusebi F (1998) The neuronal $\alpha 6$ subunit forms functional heteromeric acetylcholine receptors in human transfected cells. Eur J Neurosci 10:172-178.

Hamill OP, Marty A, Neher E, Sakmann B, Sigworth FJ (1981) Improved patch-clamp techniques for high-resolution current recording from cells and cell-free membrane patches. Pflugers Arch 391:85-100.

Hammer $\varnothing$, David AT, Ryan PT (2001) PAST: Paleontological statistics software package for education and data analysis. Palaeontologia Electronica 4:9

Harris KM, Stevens JK (1989) Dendritic spines of CA1 pyramidal cells in the rat hippocampus: serial electron microscopy with reference to their biophysical characteristics. J Neurosci 9:2982-2997.

Horch HL, Sargent PB (1995) Perisynaptic surface distribution of multiple classes of nicotinic acetylcholine receptors on neurons in the chicken ciliary ganglion. J Neurosci 15:7778-7795.

Horn R, Marty A (1988) Muscarinic activation of ionic currents measured by a new whole-cell recording method. J Gen Physiol 92:145-159.

Jacob MH, Berg DK (1983) The ultrastructural localization of $\alpha$-bungarotoxin binding sites in relation to synapses on chick ciliary ganglion neurons. J Neurosci 3:260-271.

Jacob MH, Berg DK, Lindstrom JM (1984) Shared antigenic determinants between Electrophorus acetylcholine receptor and a synaptic component on chicken ciliary ganglion neurons. Proc Natl Acad Sci USA 81:3223-3227.

Koch C, Zador A (1993) The function of dendritic spines: devices subserving biochemical rather than electrical compartmentalization. J Neurosci 13:413-422.

Landmesser L, Pilar G (1972) The onset and development of transmission in the chick ciliary ganglion. J Physiol 222:691-713.

Loring RH, Zigmond RE (1987) Ultrastructural distribution of ${ }^{125}$ I-toxin F binding sites on chick ciliary neurons: synpatic localization of a toxin that blocks ganglionic nicotinic receptors. J Neurosci 7:2153-2162.

Loring RH, Dahm LM, Zigmond RE (1985) Localization of $\alpha$-bungarotoxin binding sites in the ciliary ganglion of the embryonic chick: an autoradiographic study at the light and electron microscopic level. Neuroscience 14:645-660.

Luo S, Kulak JM, Cartier GE, Jacobsen RB, Yoshikami D, Olivera BM, McIntosh JM (1998) $\alpha$-Conotoxin AuIB selectivity blocks $\alpha 3 \beta 4$ nicotinic acetylcholine receptors and nicotine-evoked norepinephrine release. J Neurosci 18:8571-8579.

MacDermott AB, Role LW, Siegelbaum SA (1999) Presynaptic ionotropic receptors and the control of transmitter release. Annu Rev Neurosci 22:443-485.

Margiotta JF, Berg DK, Dionne VE (1987) Cyclic AMP regulates the proportion of functional acetylcholine receptors on chicken ciliary ganglion neurons. Proc Natl Acad Sci U S A 84:8155-8159.

Martin AR, Pilar G (1964) Quantal components of the synaptic potential in the ciliary ganglion of the chick. J Physiol 175:1-16.

Matsui K, Jahr CE (2006) Exocytosis unbound. Curr Opin Neurobiol 16:305-311.

McNerney ME, Pardi D, Pugh PC, Nai Q, Margiotta JF (2000) Expression and channel properties of a $\alpha$-bungarotoxin-sensitive acetylcholine re- ceptors on chick ciliary and choroid neurons. J Neurophysiol 84:1314-1329.

Nai Q, McIntosh JM, Margiotta JF (2003) Relating neuronal nicotinic acetylcholine receptor subtypes defined by subunit composition and channel function. Mol Pharmacol 63:311-324.

Nguyen D, Sargent PB (2002) Synaptic vesicle recycling at two classes of release sites in giant nerve terminals of the embryonic chicken ciliary ganglion. J Comp Neurol 448:128-137.

Olivieri-Sangiacomo C, Del Fà A, Gangitano C (1983) Acetylcholinesterase localization at synapses in chick embryo ciliary ganglion. Experientia 39: 598-600.

Picciotto MR, Addy NA, Mineur YS, Brunzell DH (2008) It is not "either/ or": activation and desensitization of nicotinic acetylcholine receptors both contribute to behaviors related to nicotine addiction and mood. Prog Neurobiol 84:329-342.

Quick MW, Lester RA (2002) Desensitization of neuronal nicotinic receptors. J Neurobiol 53:457-478.

Rae J, Cooper K, Gates P, Watsky M (1991) Low access resistance perforated patch recordings using amphotericin B. J Neurosci Methods 37:15-26.

Rogers M, Sargent PB (2003) Rapid activation of presynaptic nicotinic acetylcholine receptors by nerve-released transmitter. Eur J Neurosci 18:2946-2956.

Rosenmund C, Stevens CF (1996) Definition of the readily releasable pool of vesicles at hippocampal synapses. Neuron 16:1197-1207.

Segev I, Rall W (1988) Computational study of an excitable dendritic spine. J Neurophysiol 60:499-523.

Shoop RD, Martone ME, Yamada N, Ellisman MH, Berg DK (1999) Neuronal acetylcholine receptors with $\alpha 7$ subunits are concentrated on somatic spines for synaptic signaling in embryonic chick ciliary ganglia. J Neurosci 19:692-704.

Silver RA (2003) Estimation of nonuniform quantal parameters with multiple-probability fluctuation analysis: theory, application and limitations. J Neurosci Methods 130:127-141.

Svoboda K, Tank DW, Denk W (1996) Direct measurement of coupling between dendritic spines and shafts. Science 272:716-719.

Ullian EM, McIntosh JM, Sargent PB (1997) Rapid synaptic transmission in the avian ciliary ganglion is mediated by two distinct classes of nicotinic receptors. J Neurosci 17:7210-7219.

Vernallis AB, Conroy WG, Berg DK (1993) Neurons assemble acetylcholine receptors with as many as three kinds of subunits while maintaining subunit segregation among receptor subtypes. Neuron 10:451-464.

Vijayaraghavan S, Pugh PC, Zhang Z-W, Rathouz MM, Berg DK (1992) Nicotinic receptors that bind $\alpha$-bungarotoxin on neurons raise intracellular free $\mathrm{Ca}^{2+}$. Neuron 8:352-363.

Williams BM, Temburni MK, Levey MS, Bertrand S, Bertrand D, Jacob MH (1998) The long internal loop of the $\alpha 3$ subunit targets AChRs to subdomains within individual synapses on neurons in vivo. Nat Neurosci 1:557-562.

Wonnacott S, Barik J, Dickinson J, Jones IW (2006) Nicotinic receptors modulate transmitter cross talk in the CNS: nicotinic modulation of transmitters. J Mol Neurosci 30:137-140.

Yawo H, Chuhma N (1994) $\omega$-Conotoxin -sensitive and -resistant transmitter release from the chick ciliary presynaptic terminal. J Physiol 477:437-448.

Zhang ZW, Coggan JS, Berg DK (1996) Synaptic currents generated by neuronal acetylcholine receptors sensitive to $\alpha$-bungarotoxin. Neuron 17: 1231-1240. 